\title{
Remote Sensing and GIS Based Spectro-Agrometeorological Maize Yield Forecast Model for South Tigray Zone, Ethiopia
}

\author{
Abiy Wogderes Zinna, Karuturi Venkata Suryabhagavan* \\ School of Earth Sciences, Addis Ababa University, Addis Ababa, Ethiopia \\ Email: *drsuryabhagavan@gmail.com
}

Received 7 February 2016; accepted 25 April 2016; published 28 April 2016

Copyright (C) 2016 by authors and Scientific Research Publishing Inc.

This work is licensed under the Creative Commons Attribution International License (CC BY). http://creativecommons.org/licenses/by/4.0/

(c) (i) Open Access

\begin{abstract}
Remote-sensing data acquired by satellite imageries have a wide scope in agricultural applications owing to their synoptic and repetitive coverage. This study reports the development of an operational spectro-agrometereological yield model for maize crop derived from time series data of SPOT VEGETATION, actual and potential evapotranspiration and rainfall estimate satellite data for the years 2003-2012. Indices of these input data were utilized to validate their strength in explaining grain yield recorded by the Central Statistical Agency through correlation analyses. Crop masking at crop land area was applied and refined using agro-ecological zones suitable for maize. Rainfall estimates and average Normalized Difference Vegetation Index were found highly correlated to maize yield with the former accounting for $85 \%$ variation and the latter $80 \%$, respectively. The developed spectro-agrometeorological yield model was successfully validated against the predicted Zone level yields estimated by Central Statistical Agency $\left(r^{2}=0.88, R^{2}\right.$ SE $=1.405 \mathrm{q} \cdot \mathbf{h a}^{-1}$ and $21 \%$ coefficient of variation). Thus, remote sensing and geographical information system based maize yield forecast improved quality and timelines of the data besides distinguishing yield production levels/areas and making intervention very easy for the decision makers thereby proving the clear potential of spectro-agrometeorological factors for maize yield forecasting, particularly for Ethiopia.
\end{abstract}

\section{Keywords}

Ethiopia, Forecast Model, GIS, Maize Yield, NDVI, Remote Sensing, RFE

\footnotetext{
${ }^{*}$ Corresponding author.
} 


\section{Introduction}

Agriculture is the backbone of Ethiopian economy providing livelihood to $~ 84 \%$ population besides contributing $45 \%$ to the Gross Domestic Product and $86 \%$ to export earnings [1]. As such, reliable, accurate and timely information on various crops raised, their extent, growth and yield forecast form vital components of planning in efficient resources management. Such knowledge is all the more important, especially in regions characterized by climatic uncertainties to enable planners and decision makers to assess the quantum of imports required in case of a shortfall or alternatively the volume of exports possible during surplus. Such prediction further facilitates government to put in place strategic contingency plans for redistribution of food grains during famine [2].

In Ethiopia, two methods are followed to monitor and forecast crop yields. The first is Crop Yield Monitoring and Forecasting System (CYMFS) run by the Ethiopian National Meteorological Agency (NMA) in conjunction with the European Union's Joint Research Council (JRC) and the Food and Agricultural Organization (FAO). The system relies on empirical Crop Specific Water Balance (CSWB) model of FAO rather than process based crop simulation model. The model is less likely to capture complex interactions between climate and crop and hence considered as deficient [3]. The second method followed by the Ethiopian Government involves data collection from stakeholders on predicted crop yield and comparing it with previous year's yield as recorded by the Central Statistical Agency [4]. Although this data are widely used by decision makers official statistics is highly subjective and dependent on the agenda of stakeholders [3] [5]. Under these circumstances, it is desirable to develop and adopt scientifically sound and technologically advanced yield prediction techniques to arrive at dependable forecasting systems.

Vegetation indices derived from remote sensing are considered as potential tools to improve simulations in real-time. Though remote sensing data alone have been used in different parts of the world to estimate crop yields [6] [7], it is observed that in addition to vegetation indices, rainfall distribution in space and time shall be incorporated into the models. Such hybrid models, besides bearing higher correlation; enable better predictive capability than simple models. In fact, latest agro-meteorological models consider solar radiation, temperature, humidity and soil water availability while introducing information on crop management, varieties and stresses from the spectral components. Previous work in the line has proved the relevance of low resolution satellite images for crop monitoring and yield prediction at the regional level, especially because of the low cost involved [8]. Taking these aspects into consideration, development of an operational spectro-agrometeorological yield model for maize in South Tigray Zone of Tigray Regional State of Ethiopia was attempted in the present instance based on spectral index, normalized difference vegetation index, meteorological data and official statistics of CSA.

\section{Study Area and Methods}

\subsection{Study Area}

The study area, South Tigray Zone lying at an altitude of 1156 to $3671 \mathrm{~m}$ asl is situated between $12^{\circ} 15^{\prime} 16^{\prime \prime} \mathrm{N}$ $13^{\circ} 38^{\prime} 45^{\prime \prime} \mathrm{N}$ and $38^{\circ} 59^{\prime} 33^{\prime \prime E ~-~ 39 ~} 53^{\prime} 20^{\prime \prime E}$ extending to $9432 \mathrm{~km}^{2}$ (Figure 1). According to NMA reconstructed data from ground findings, remote sensing observations and other proxies for 1981-2010, the monthly minimum temperature of the Zone ranges from $10.2^{\circ} \mathrm{C}$ in December to $14.8^{\circ} \mathrm{C}$ in June while maximum temperature extends from $24.5^{\circ} \mathrm{C}$ in January to $29.5^{\circ} \mathrm{C}$ in June. Annual mean rainfall in the area varies from $10 \mathrm{~mm}$ in November to $210 \mathrm{~mm}$ in August and is characterized by a bimodal pattern represented by short rainy season during March-April and prolonged rainy season from June to September with a peak in August.

\subsection{Methods}

The present work was carried out based on satellite imageries, Ethiopian Mapping Agency maps and other collateral data obtained from various organizations of the Federal Government of Ethiopia besides verified ground truths. The data were analyzed and maize yield forecast areas mapped using Remote Sensing (RS) and Geographical Information System (GIS). Data integration and further processing in developing the spectro-agrometeorological model adopted during the present work are represented in the form of a flow chart (Figure 2).

\subsection{Satellite Data}

Different satellite imageries and models, viz., SPOT VEGETATION (SPOT VEG), rainfall estimates (RFE), 


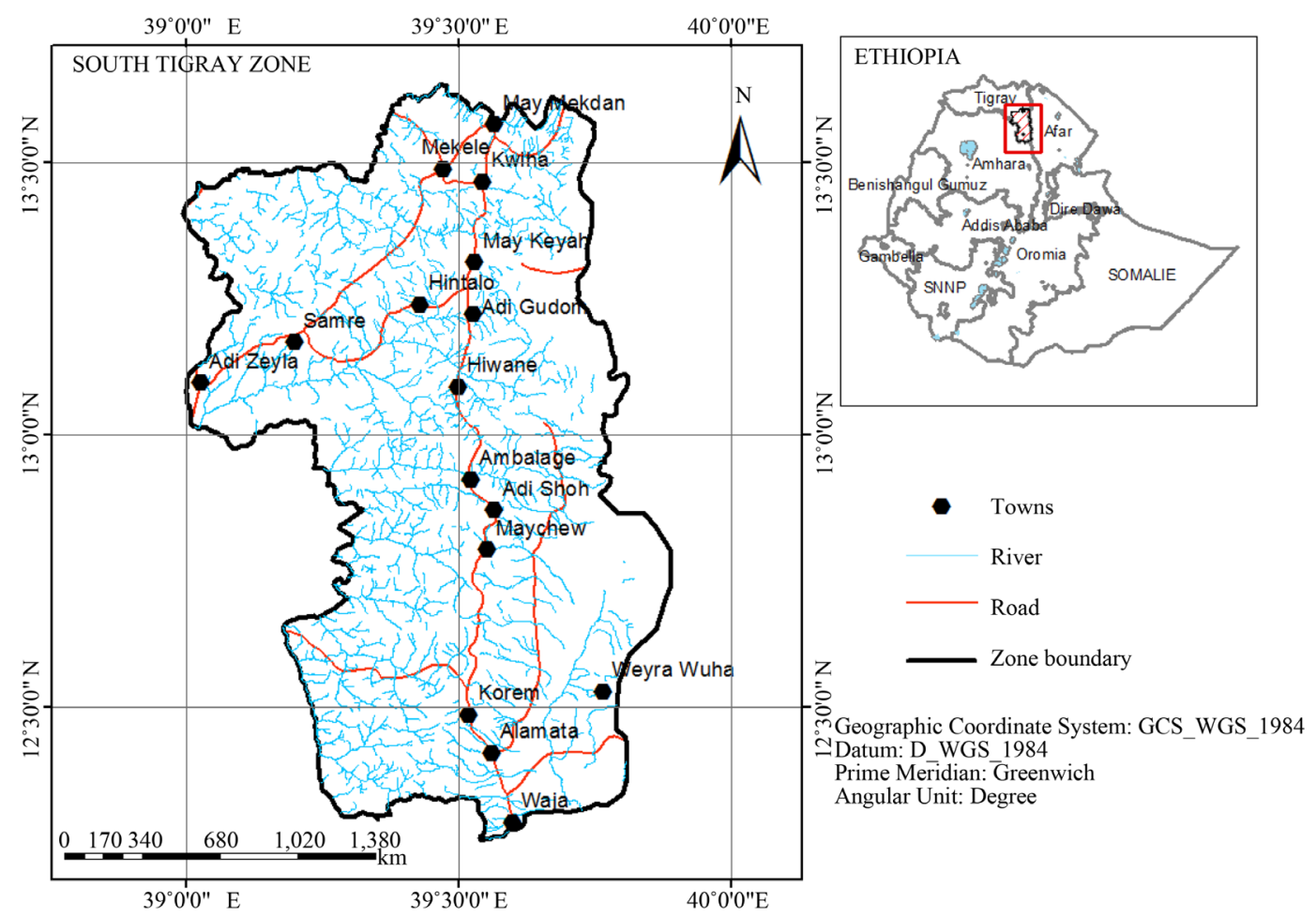

Figure 1. Location map of the study area.

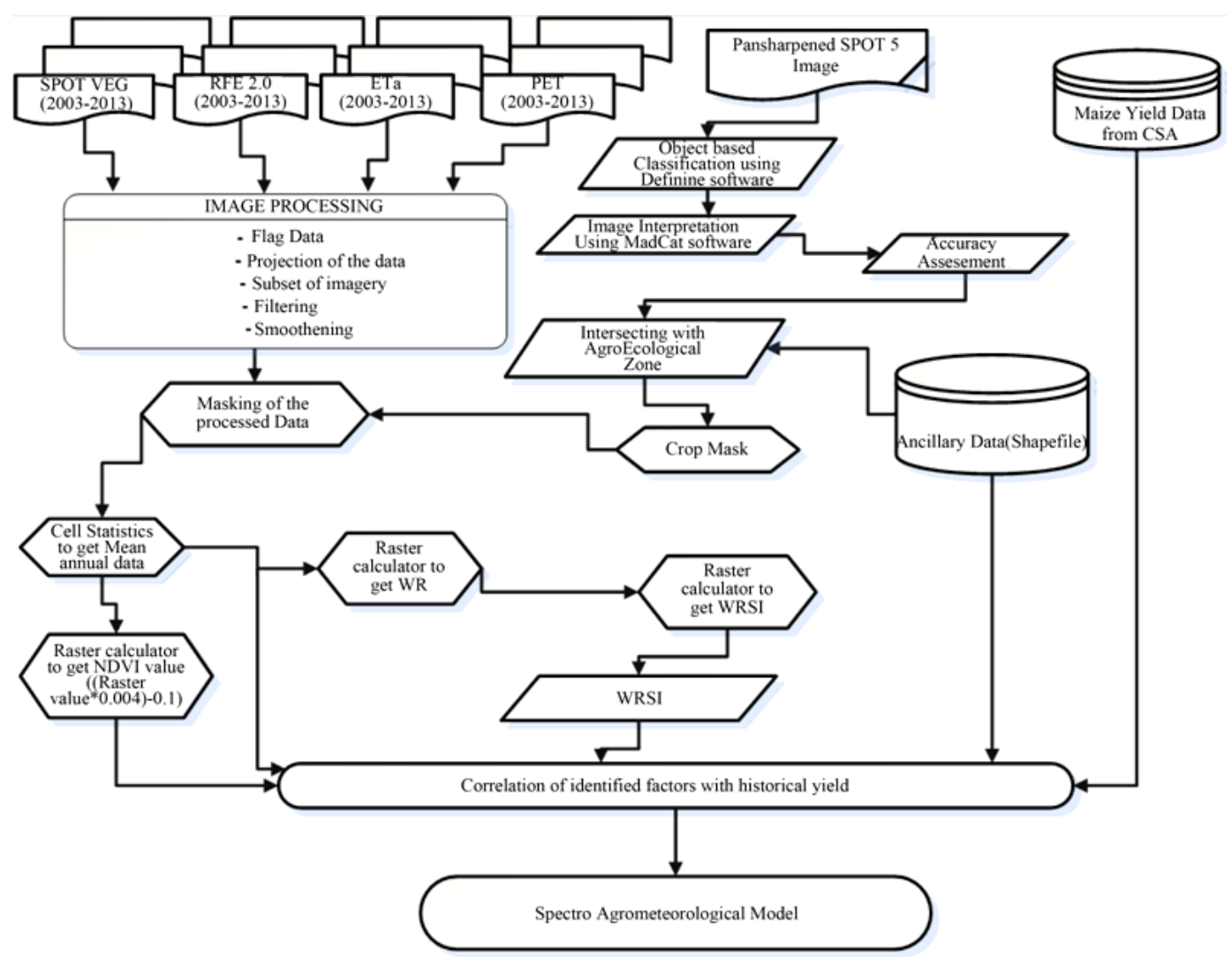

Figure 2. Steps followed in developing spectro-agrometeorological model. 
water requirement satisfaction index (WRSI) and SPOT 5 imagery were made use of in the study. Satellite data obtained were digitally rectified and processed using ERDAS Imagine 9.2 version.

\subsection{Normalized Difference Vegetation Index}

SPOT VEGETATION was launched in March 1998 on board SPOT 4 satellite to monitor surface parameters on global basis at daily intervals at $1 \mathrm{~km}$ resolution [2] [9] [10]. From such time series imageries between (20032012, daily (S1) and decadal (S10) mosaics of SPOT VEG were synthesized employing "Spirit" software and NDVIs derived [11].

\subsection{Rainfall Estimate}

Rainfall data, currently used by Famine Early Warning System (FEWSNET), FAO and World Food Programme (WFP) for agricultural monitoring in several African countries were derived from rainfall estimate (RFE) product of National Oceanic and Atmospheric Administration's (NOAA) climate prediction center. Rainfall estimates are available for two different time spans in two versions, viz., RFE 1.0 and RFE 2.0. RFE 1.0 relying on interpolation method to combine Meteosat and Global Telecommunication System data is available for the period 1995-2000. RFE 2.0 imbibing additional techniques along with cold cloud duration and station rainfall to refine precipitation estimates is available from 2001 onwards and is more reliable than rainfall data of European Center for Medium Range Weather Forecast (ECMWF) [9]. Therefore, RFE 2.0 satellite rainfall estimate for the period 2003-2012 was utilized during the present work [11].

\subsection{Water Requirement Satisfaction Index}

Water requirement satisfaction index was calculated as the ratio of seasonal actual evapotranspiration (ETa) to the seasonal crop water requirement (WR) based on the water availability and crop requirement during growing season [1].

$$
\mathrm{WRSI}=(\mathrm{ETa} / \mathrm{WR}) \times 100
$$

Actual evapotranspiration (ETa), as opposed to the potential evapotranspiration (PET); represents actual amount of water withdrawn from soil water reservoir. When soil water hold remains above the maximum allowable depletion (MAD) level (based on crop type), ETa equals WR and no water stress is experienced. But, when soil water level goes below MAD level, ETa will be lower than WR in proportion to the remaining soil water volume indicating water stress [12]. Crop water requirement was calculated from the Penman-Monteith's PET using the crop coefficient (Kc) to adjust for the growth stage of the crop [2].

$$
\mathrm{WR}=\mathrm{PET} \times \mathrm{Kc}
$$

\section{Results}

\subsection{Correlations between Various Parameters and Maize Yield}

Correlation between various spectro-agrometeorological parameters, namely, NDVI actual (NDVIa), NDVI cumulative (NDVIc), NDVI crop cycle (NDVIx), REF, WRSI, Eta and ETa total were found out using individual correlation/linear regression statistics.

\subsection{Correlation between NDVI Variables and Maize Yield}

Correlation between different NDVI variables and maize yield showed that NDVIa was significantly correlated to the yield $(\mathrm{r}=0.80, p=0.02)$ while NDVIc $(\mathrm{r}=0.44, p=0.28)$ and NDVIx $(\mathrm{r}=-0.03, p=0.94)$ were not significantly correlated (Figures 3-5). As NDVIa also satisfied the assumption of linearity, the same was selected for multiple linear regression model development.

\subsection{Correlation between RFE and Maize Yield}

Rainfall estimate and the yield were highly significantly correlated $(r=0.85, p=0.01)$ to each other while assuming linear relationship and therefore selected for multiple linear regression model development (Figure 6). 


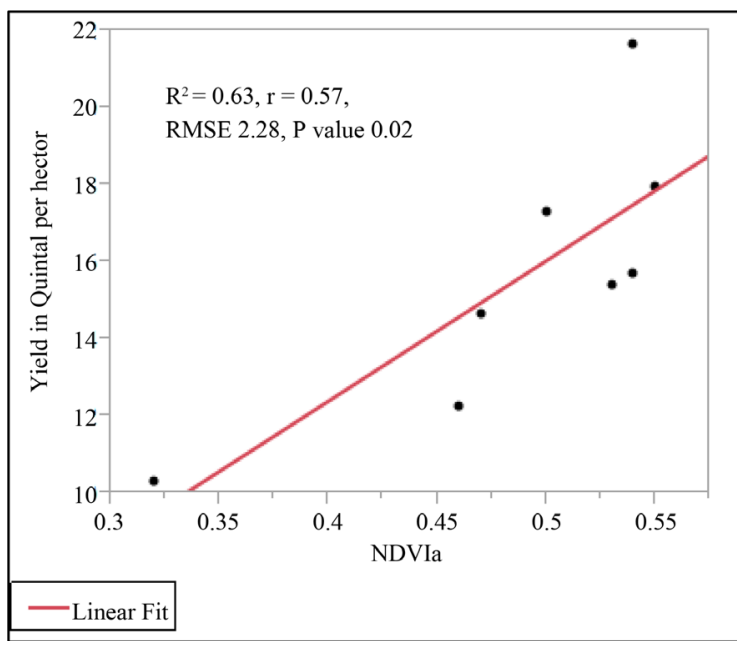

Figure 3. Maize yield as a function of NDVIa.

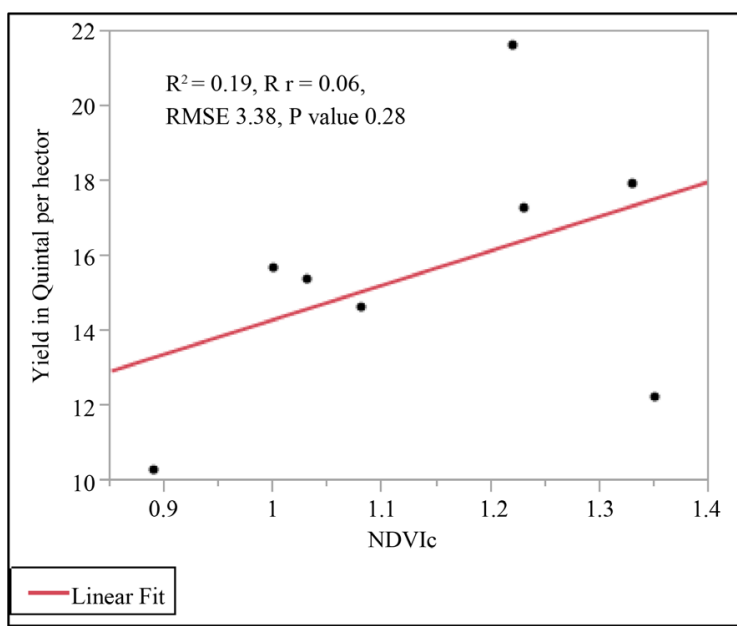

Figure 4. Maize yield as a function of NDVIc.

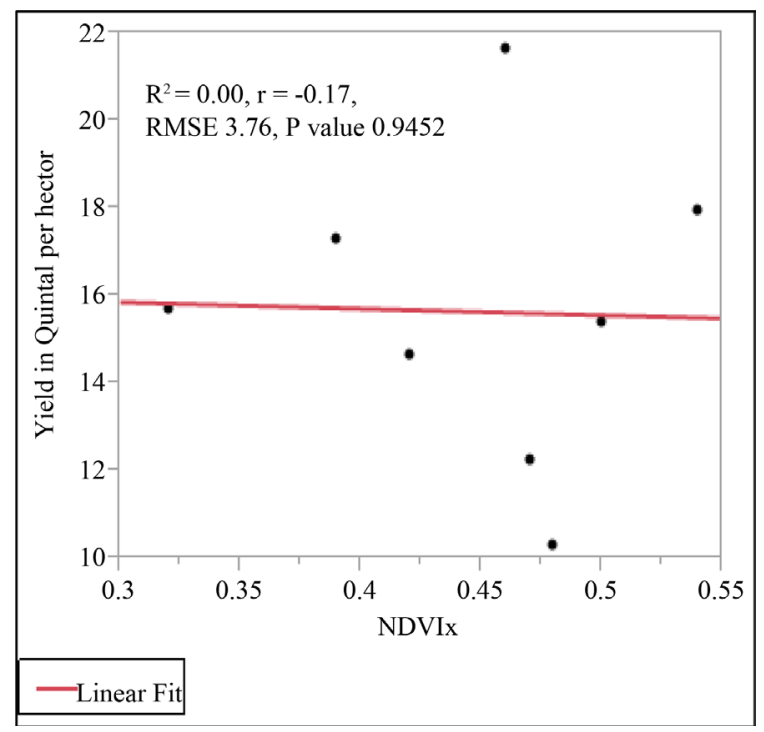

Figure 5. Maize yield as a function of NDVIx. 


\subsection{Correlation between WRSI and Maize Yield}

Correlation between WRSI and the yield reflected no significant correlation between them $(r=0.44, p=0.28)$ and hence not considered for multiple linear regression model development (Figure 7).

\subsection{Correlation between ETa Variables and Maize Yield}

Correlation between average or total ET and the yield indicated no significant correlation in either case $(\mathrm{r}=0.45$, $p=0.26 ; \mathrm{r}=0.58, p=0.13$; respectively) and hence not considered for multiple linear regression model (Figure 8 \& Figure 9).

\subsection{Multiple Linear Regression Model for Yield Forecasting}

From the above seven variables, the significantly correlated factor NDVIa and the highly significantly correlated

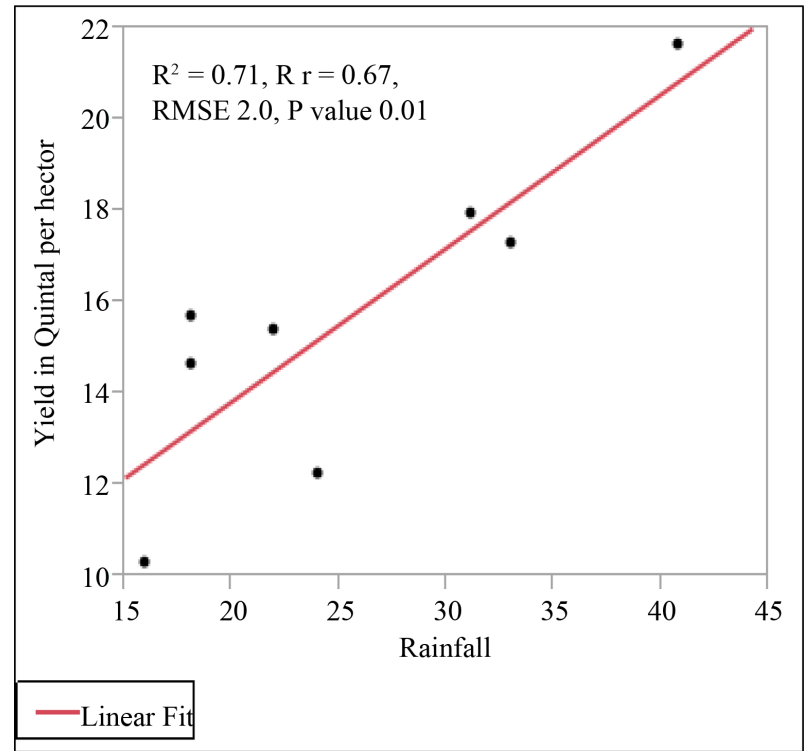

Figure 6. Maize yield as a function of RFE.

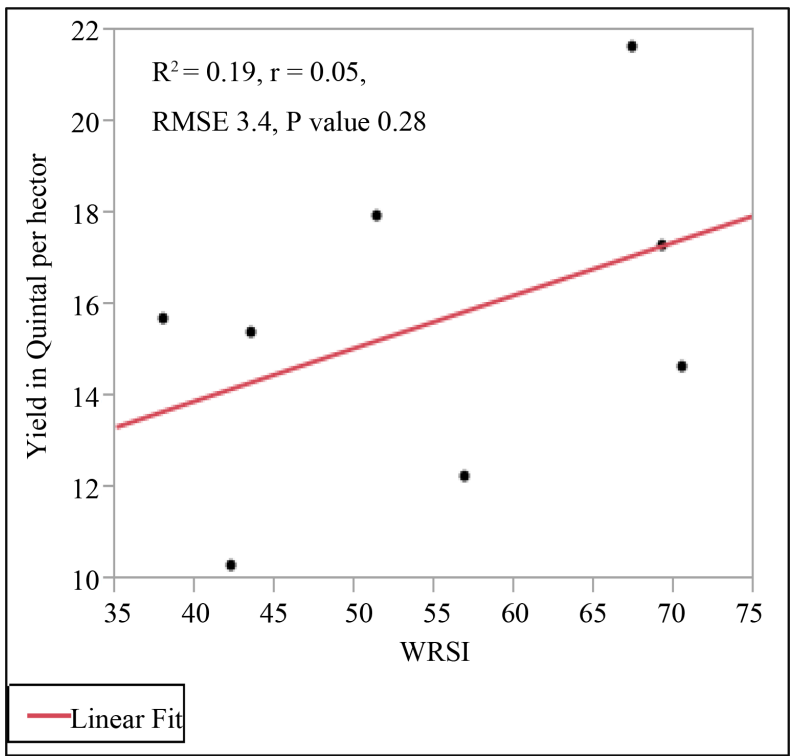

Figure 7. Maize yield as a function of WRSI. 


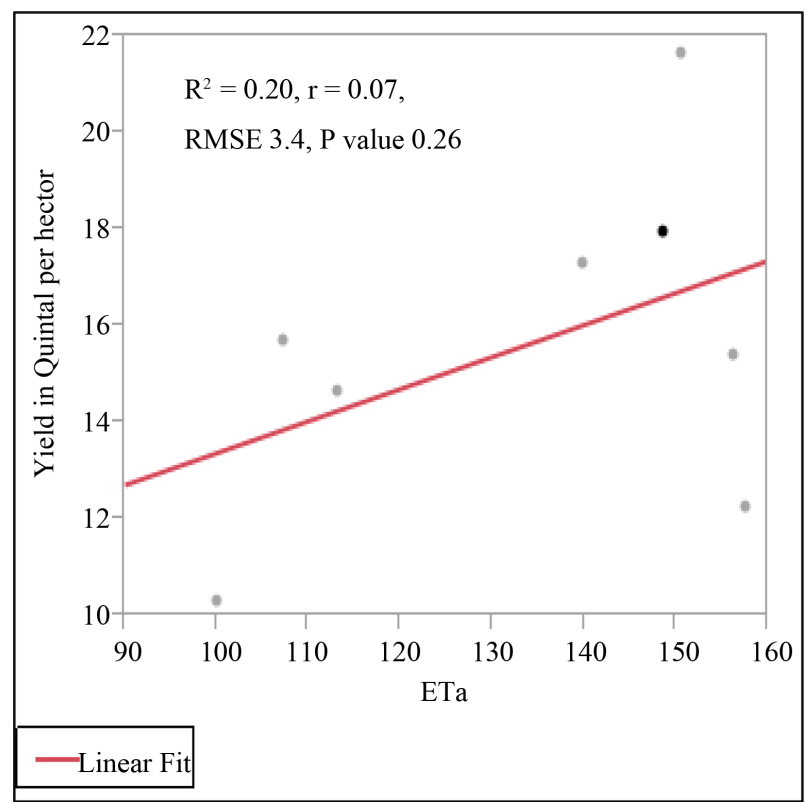

Figure 8. Maize yield as a function of Eta.

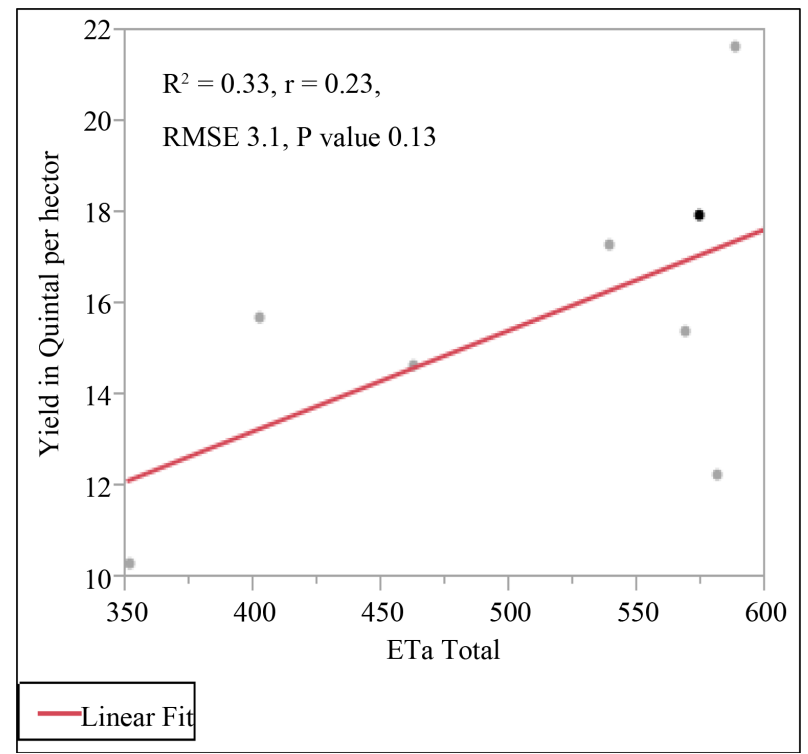

Figure 9. Maize yield as a function of ETa total.

parameter REF were used to create a MLRM. This multiple regression generated the following equation.

$$
\text { Predicted Maize Yield }\left(\mathrm{q} \cdot \mathrm{ha}^{-1}\right)=-1.06+(21.99 \times \text { NDVIa })+(0.24 \times \mathrm{REF})
$$

This resultant model was validated on the basis of coefficient of determination $\left(\mathrm{R}^{2}\right)$, root mean square error (RMSE) and coefficient of variation (CV) with values each of 0.88 (adjusted $\left.\mathrm{R}^{2}=0.84\right), 1.405\left(\mathrm{q} \cdot \mathrm{ha}^{-1}\right.$ ) and 0.94 , respectively at $99 \%$ confidence level $(p=0.005)$ evidently indicating that the maize yield prediction of the model is very good (Figure 10). The regression plot also revealed that most of the values lie fairly close to $45^{\circ}$ (exact prediction) line. In addition, analysis of variance (ANOVA) of the maize yield forecast model unraveled the significant ability ( $p=0.005$ ) of MLRM in the prediction (Table 1 ).

Further, the parameter estimates of the model confirmed that RFE bears high predictive capability than NDVIa as found earlier from high significant correlation between maize yield and REF as against significant 


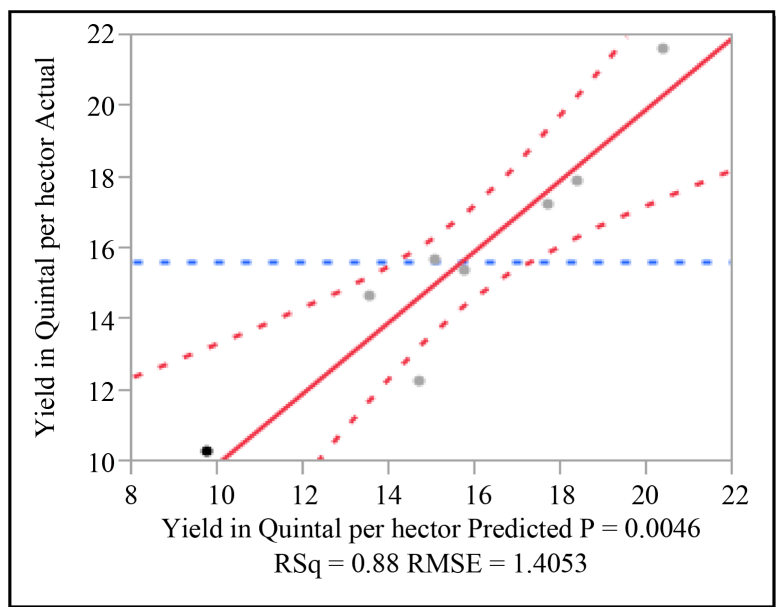

Figure 10. Actual yield from spectro-agrometerological model as a function of predicted yield.

Table 1. ANOVA of maize yield forecast model.

\begin{tabular}{cccccc}
\hline Source & DF & Sum of squares & Mean of squares & F & $p$ \\
\hline Model & 2 & 75.00 & 37.50 & 18.99 & $0.005^{* *}$ \\
Error & 5 & 9.87 & 1.98 & & \\
Total & 7 & 84.87 & & $*$ Highly significant
\end{tabular}

DF-Degrees of freedom, F-Fisher ratio, $p$ - Probability.

correlation between maize yield and NDVIa (Table 2).

\subsection{Evaluation of Conventional Crop Yield Forecast Using the Developed Model}

Evaluation of conventional crop yield forecast using the developed model showed close alliance between the two (Figure 11). According to CSA report, conventional maize yield forecast approach revealed coefficient of variation to be $22 \%$ [13] the acceptable degree of confidence 30\% despite its subjective nature whereas remote sensing supported model showed $21 \%$ coefficient of variation with acceptable degree of confidence (99\%).

\subsection{Maize Crop Forecast for the Year 2013}

Based on the developed prediction model, highest maize yield for 2013 is expected to be $20.63 \mathrm{q} \cdot \mathrm{ha}^{-1}$ and lowest $11.84 \mathrm{q} \cdot \mathrm{ha}^{-1}$ with a mean of $16.2 \mathrm{q} \cdot \mathrm{ha}^{-1}$. The prediction also indicates that maize yield in $64.1 \%$ of the study area will be 12 - $16 \mathrm{q} \cdot \mathrm{ha}^{-1}$ and in $26.3 \%$ of the area to be $17-18 \mathrm{q} \cdot \mathrm{ha}^{-1}$ while the rest of $9.6 \%$ area is likely to yield 19 - $21 \mathrm{q} \cdot \mathrm{ha}^{-1}$ (Table 3).

Spatial distribution of the production levels in South Tigray zone reveal that certain pockets of south-western part of the study area (Ofla Woreda) are most productive with $19-21 \mathrm{q} \cdot \mathrm{ha}^{-1}$ of yield while many stations in the north-west and south-east are intermediately productive with $17-18 \mathrm{q} \cdot \mathrm{ha}^{-1}$ of output. The entire eastern half of the study area also hosts least productive pockets giving only $12-16 \mathrm{q} \cdot \mathrm{ha}^{-1}$ of grains (Figure 12). Data available at the Zone Agricultural Office also confirm that Ofla Woreda is most productive area of the Zone.

\section{Discussion}

Spatial information derived from physiological crop models had demonstrated the expected accuracy of crop yield estimates to be $\pm 10 \%$ - 15\% [14] [15]. Compared to conventional physiological or agro-meteorological crop models, spectro-agrometeorological crop yield models require less number of input variables. While the former is highly vulnerable to subjectivity, the latter avoids bias and ensures reasonable degree of consistency both in time and space [16]. Moreover, remote sensing based forecast can be provided by September end during flowering stage as against December in the case of "conventional data calendar" release though the latter includes 
Table 2. Parameter estimates of the maize forecast model.

\begin{tabular}{ccccc}
\hline Term & Estimate & Standard error & $\mathrm{t}$ & $p$ \\
\hline Intercept & -1.06 & 3.47 & -0.31 & 0.77 \\
NDVIa & 21.99 & 8.25 & 2.67 & $0.05^{*}$ \\
RFE & 0.24 & 0.07 & 3.29 & $0.02^{*}$ \\
\hline
\end{tabular}

t-Student's ratio, $p$-Probability, ${ }^{*}$-Significant.

Table 3. Maize production forecast for south Tigray zone for the year 2013.

\begin{tabular}{ccc}
\hline Production level & Crop coverage area (\%) & Yield forecast $\left(\mathrm{q} \cdot \mathrm{ha}^{-1}\right)$ \\
\hline I & 9.6 & $19-21$ \\
II & 26.3 & $17-18$ \\
III & 64.1 & $12-16$ \\
\hline
\end{tabular}

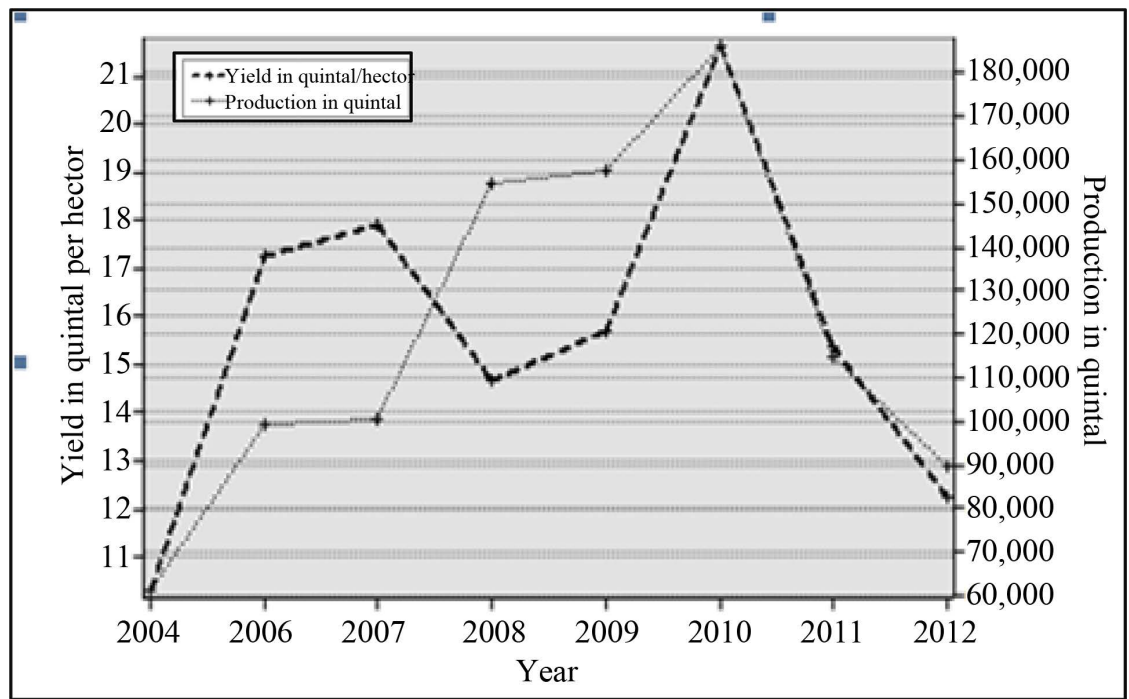

Figure 11. Evaluation of conventional crop yield $\left(\mathrm{q} \cdot \mathrm{ha}^{-1}\right)$ forecast using the developed model.

all cereal crops. Thus, timelines issue can also be addressed effectively by remote sensing based approach even after considering all cereals included by CSA. Meteorological information from CSWB model, Crop Production System Zone (CPSZ) and real time satellite data are highly useful for crop yield forecast depicting the potential of spectro-agrometeorological factors [9], and these facts are further confirmed during the present study.

Evapotranspiration total and NDVIc were the most suitable factors for developing a multiple linear regression model in Kenya [9]. The author deciphered that ETa total with 73\% and NDVIc with $87 \%$ correlation coefficient had explained $83 \%$ of the yield variance (RMSE $=0.333 \mathrm{t} \cdot \mathrm{ha}^{-1}$ and $\mathrm{CV}=21 \%$ ) thereby proving that spectro-agrometeorological model is possible even for fragmented agricultural lands, as in the present instance. Geospatial Water Requirement Satisfaction Index (GEOWRSI) is a tool that can be used for reliable and early estimation of maize production in Kenya [10]. These authors and [17] utilized WRSI to derive reliable crop yield estimates. However, in the present findings this parameter was not useful for inclusion in the model (due to its minute correlation coefficient coupled with insignificant $p$ relation with maize yield) possibly due to distinct geo-climatic conditions.

Thus, remote sensing and geographical information system based maize yield forecast improved quality of the data, timelines of the prediction, facilitated differentiation of yield production levels and aided in discrimination of productive areas thereby paving the way easy for administrators to intervene in timely decision making further to demonstrating the clear potential of spectro-agrometeorological factors in yield forecasting. 


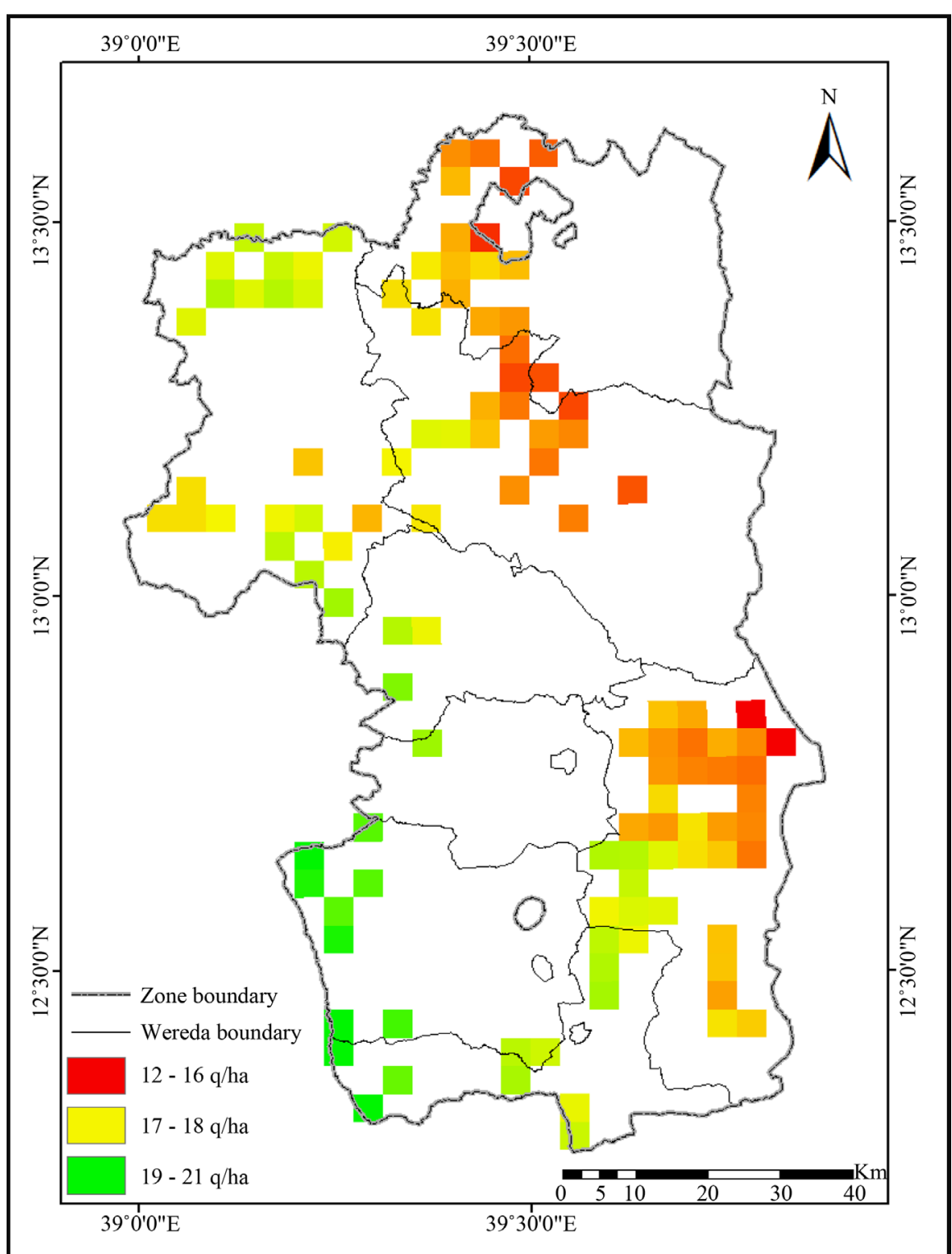

Figure 12. Maize yield forecast map of south Tigray zone in Ethiopia for the year 2013.

\section{Conclusion}

In order to ease natural resources management practices in South Tigray Zone, a maize yield forecast model was developed from two most relevant spectro-agrometeorological variables, viz., REF and NDVIa. The developed model has a predictive capability of 0.88 with RMSE $1.405 \mathrm{q} \cdot \mathrm{ha}^{-1}$ and is quite encouraging, especially in view of the existence of fragmented cultivation plots. Preparation of a forecast map indicating productive areas and production levels for the ensuing year was also feasible. Through this model, forecast is possible in advance in September during flowering season itself as against that in December by the conventional method. Decision makers can identify relative productive areas coupled with yield quantum well in advance of harvest. So, development of agriculture yield prediction tools based on state-of-the-art technologies is crucial for timely interventions to safeguard the interests of the nation and its populace.

\section{Acknowledgements}

The authors wish to express their sincere thanks to the School of Earth Sciences and the College of Natural 
Sciences, Addis Ababa University for providing all the necessary facilities and support during the study period. The authors would like to express appreciation to the reviewers for their comments to the manuscript.

\section{References}

[1] FDRE (2013) Federal Democratic Republic of Ethiopia. http://www.ethiopia.gov.et/web/Pages/Economy

[2] Sawasawa, H. L. A. (2003) Crop Yield Estimation: Integrating Remote Sensing, GIS and Management Factors: A Case Study of Birkoor and hortgiri mandals-Nizambad District, India. MSc Thesis, ITC, Enschede.

[3] Greatrex, H. (2012) The Application of Seasonal Rainfall Forecasts and Satellite Rainfall Estimates to Seasonal Crop Yield Forecasting for Africa. PhD Thesis, University of Reading, Reading.

[4] CSA (2012) Central Statistical Agency. http://www.csa.gov.et/index.php/2013-02-20-13-43-35/national-statistics-abstract/141-population

[5] Beyene, E.G. and Meissner, B. (2010) Spatio-Temporal Analyses of Correlation between NOAA Satellite RFE and Weather Stations Rainfall Record in Ethiopia. Applied Earth Observation and Geoinformation, 12, 69-75. http://dx.doi.org/10.1016/j.jag.2009.09.006

[6] Hastings, D.A. and Emery, W.J. (1992) The Advanced Very High Resolution Radiometer (AVHRR): A Brief Reference Guide. Photogrammetric Engineering \& Remote Sensing, 58, 1183-1888.

[7] Prasad, K., Chai, L., Singh, P. and Kafatos, M. (2007) Use of Vegetation index and Meteorological Parameters for the Prediction of Crop Yield in India. International Journal of Remote Sensing, 28, 5207-5235. http://dx.doi.org/10.1080/01431160601105843

[8] Rembold, F., Atzberge,r C., Savin, I. and Rojas, O. (2013) Using Low Resolution Satellite Imagery for Yield Prediction and Yield Anomaly Detection. Remote Sensing, 5, 1704-1733. http://dx.doi.org/10.3390/rs5041704

[9] Rojas, O. (2007) Operational Maize Yield Model Development and Validation Based on Remote Sensing and Agrometereological Data in Kenya. International Journal of Remote Sending, 28, 3775-3793. http://dx.doi.org/10.1080/01431160601075608

[10] Rijks, O., Massart, M., Rembold, F., Gommes, R. and Leo, O. (2007) Crop and Rangeland Monitoring in Eastern Africa. Proceedings of the 2nd International Workshop, Nairobi, 28-30 January 2007, 95-104.

[11] Eerens, H., Haesen, D., Rembold, F., Urbano, F., Tote, C. and Bydekerke, L. (2014) Image Time Series Processing for Agricultural Monitoring. Environmental Modelling \& Software, 53, 154-162. http://dx.doi.org/10.1016/j.envsoft.2013.10.021

[12] Gelassie, T.Y. (2012) Remote Sensing Evapotranspiration Using Geonet Cast and Insitu Data Streams for Drought Monitoring and Early Warning: Case Study for the Amhara region in Ethiopia. Unpublished MSc Thesis, University of Twenty, Enschede.

[13] CSA (2013) Central Statistical Agency, Annual Agricultural Report. http://www.csa.gov.et/index.php/2013-02-20-13-43-35/2013-02-20-13-45-32/annual-agricultural-sample-survey

[14] Carbone, G.J., Narumalani, S. and King, M. (1996) Application of Remote Sensing and GIS Technologies with Physiological Crop Models. Photogrammetrlc Engineering and Remote Sensing, 62, 171-179.

[15] Thornton, P.K., Bowen, W.T., Ravelo, A.C., Wilkens, P.W., Farmer, G., Brock, J. and Brink, J.E. (1997) Estimating millet Production for Famine Early Warning: An Application of Crop Simulation Modeling Using Satellite and GroundBased Data in Burkina Faso. Agricultural and Forest Meteorology, 83, 95-112. http://dx.doi.org/10.1016/S0168-1923(96)02348-9

[16] Gommes, R. (2001) An Introduction to the Art of Agro Meteorological Crop Yield Forecasting Using Multiple Regression. Unpublished Document, FAO, Dhaka, 38.

[17] Manatasa, D., Nyakudya, W., Mukwada, G. and Matsikwa, H. (2011) Maize Yield Forecasting for Zimbabwe Farming Sectors Using Satellite Rainfall Estimates. Natural Hazards, 59, 447-463. http://dx.doi.org/10.1007/s11069-011-9765-0 